\title{
Experience of Ubiquitous Computing Technology Driven Mobile Commerce in Africa: Impact of Usability, Privacy, Trust, and Reputation Concern
}

\author{
https://doi.org/10.3991/ijim.v12i3.7905 \\ Sunday Adewale Olaleye ${ }^{(\varpi)}$ \\ University of Oulu, Oulu, Finland \\ sunday.olaleye@oulu.fi \\ Solomon Sunday Oyelere, Ismaila Temitayo Sanusi \& Agbo Friday Joseph \\ University of Eastern Finland, Joensuu, Finland
}

\begin{abstract}
- the concept of ubiquitous computing allows the seamless: anywhere, anytime, anyone interaction of computing devices and technology. Ubiquitous commerce simply known as u-commerce is an evolution of commerce based on recent innovations and advancement in computing technology. The aim of this study is to understand the impact of ubiquitous computing technologies on users, with a special focus on ubiquitous commerce. The study used the quantitative method and targeted the mobile device users for online shopping in Nigeria with convenience sampling technique. The data was analyzed using SmartPLS 2.0 with partial least square structural equation modelling. The study results confirmed the significant role of trust as a mediator between the reputation and u-commerce user's experience, and usability and privacy directly predict the ubiquitous commerce user's experience. The study advances with managerial implications, pinpointed limitations, and propose future studies.
\end{abstract}

Keywords—ubiquitous commerce, ubiquitous computing, mobile commerce, technology, user experience

\section{Introduction}

The pervasiveness of computers, the internet, and technology on the globe has significant influence on a different facet of the society: governance, economy, commerce, education, industry, and healthcare. Ubiquitous computing is a principle in computer science and software engineering where computing power is made to appear anytime and everywhere using any device in any format. The concept of ubiquitous computing allows the seamless: anywhere anytime anyone interaction of computing devices and technology. Ubiquitous commerce simply known as u-commerce is an evolution of commerce based on recent innovations and advancement in computing technology. Conceptually, it is an extension of electronic commerce (e-commerce), and mobile commerce (m-commerce) [50]. The advancement of technology and its application to the industrial growth of commerce can be traced to common elements 
that exist between ubiquitous computing and ubiquitous commerce as revealed by Watson et al. [53], Junglas and Watson, [27]. These elements are called u-construct, ubiquity, uniqueness, universal, and unison [53] [27]. Some of the factors affecting the adoption and usability of $\mathrm{u}$-commerce in the society were discussed to consist of familiarity with the technology, policy, and security concern Hi and Wie [53]. Though these concerns are universal, however, African countries such as Nigeria have shown far-reaching issues affecting the application of ubiquitous computing technologies, especially to the commerce sector. Most African countries have poor infrastructure to sustain the dynamism of computing technologies and growing consumers' population, and issues with privacy, trust, security, and usability are common. For example, the information on the total number of Nigerian active subscribers of internet data services utilizing GSM technologies in May 2017 indicated more than 91 million (country of 190 million people [61]) in comparison to a total of more than 38 million in May 2013, showing 58\% increase within the period of 3 years [41]. Moreover, it has been estimated that by the year 2050 Nigeria will be the third largest country in the world [59], without commensurate infrastructural development. However, the huge population and active population workforce could steer growth, but only if there is a corresponding investment in the commercial sector of Nigeria. It is only this conditional development that could allay the fears of consumers willing to adopt $\mathrm{u}$ commerce. Therefore, it is time to commence building a formidable foundation for the future of technology-driven African society.

The aim of this study is to understand the impact of ubiquitous computing technologies on users, with a special focus on u-commerce. Furthermore, the study will unravel users' experience in u-commerce and the existing relationship between usability, privacy, trust, and reputation as important components of u-commerce.

\section{Theoretical background and hypotheses development}

\subsection{Ubiquitous computing and commerce in Nigeria}

Over the years, technology has grown from generation to generation. In the early 19 's, mainframe computers dominated the computing scene based on the principle of one computer serving many people. Today we have a countless number of computers interconnected for sharing information seamlessly, which was the conceived idea of Mark Weiser in 1988 at the Computer Science Lab at Xerox PARC. According to Jaydip, ubiquitous computing has few challenges that are inherent in the technology that affects its deployment across the world [30]. These challenges are categorized as technical, social and economic, which posed a serious limitation to the embracing and adoption of u-computing in the developing countries [60]. The issues of interoperability between different available devices and platforms have a great impact on wider acceptation of u-computing in developing countries. Socially, many developing countries including Nigeria have not gotten it all right in their approach to policy formulation and legal framework that can critically take care of data integrity and privacy. While privacy and integrity of data may not be the primary concern in the production 
of services, users are skeptical of the integrity of their data, and this creates suspicion and distrust that has hampered full deployment of u-computing. Again, the level of infrastructural development for instance power and internet connectivity in the domain of discussion is not sufficient to cater and sustain the implementation of ubiquitous computing. Apart from social and technical issues, the economic situation of a country has a great impact on the adoption of ubiquitous computing which should have a direct benefit on the socio-economic development of such country. Amidst all these challenges, Nigeria and indeed other African countries are exploiting the advancement in technology thereby embracing u-commerce as the future for a sustainable economic environment.

Globally, the history of e-commerce will not be complete without the E-bay, Dell, Amazon, and other big household names in e-commerce. The transformation of the internet in 1991, which led to its commercial use usher in e-commerce with electronic selling and buying via Electronic Data Interchange (EDI) and Electronic Funds Transfer (EFT). These technologies facilitate information sharing and electronic business transactions [9]. Since the emergence of these technologies the internet has been used for several purposes and gaining popularity steadily. In 1994, the Hypertext Protocol and Digital Subscriber Line surfaced for quick accessibility and connection to the internet [9]. The year 2000, connect some companies in the United States and Western Europe to display their services on the web while the story changed to a record of $\$ 700$ billion transactions from the emergent of Business-to-Business (B2B) model [9]. E-commerce is progressive and, presently, there are springing up models such as Business-to-Customers (B2C), Business-to-Government (B2G). The revolution of the internet, world-wide-web, and ubiquitous computing has brought innovation to the developing countries, and this development is influencing e-commerce despite the limitation of infrastructural facilities such as regular power supply, fast internet connectivity, secure online payment systems, and efficient logistics. The story of hawking, street vending, small retail store shopping, shopping mall buying and selling has metamorphosed to the online store to save time and create a scalable business that facilitates all round the clock business transactions. Nigeria is among the leading African countries that witnessed the emergence and growing e-commerce, $\mathrm{m}$ commerce and now ready for u-commerce, which is pervading the online business in the developed countries [28]. Electronic commerce began to make a wave in Nigeria in less than a decade, and its landmark in tapping from the emerging wealth of a developing country is outstanding. Nigeria is making progress in online business transactions, but shopping convenience, price, and shopping experience are among the motivating factors of adopting online shopping while delivery time, internet connectivity, lack of legislation on cyber-crimes and security issues constitutes the inhibitors of online shopping in the context of developing nations [47]. Payment for goods purchased is a problem in Africa and cash on delivery is the common method of payment in Nigeria. This risky payment in Africa is contrary to the cashless economy of the developed countries [47]. E-commerce is contributing to the economy of Nigeria by engaging the jobless. For instance, Jumia one of the leading e-commerce merchants in Nigeria has more than 3000 native employees, and this economic impact is common with other e-commerce merchants in Nigeria as the total job created by the e- 
commerce merchants accrue to more than 12,000 employees since 2012 [47][28][2]. To improve their customers and vendors experience, the e-commerce merchants have been making use of direct messaging, live chat, snap and share with mobile apps, referral program, and online badges to classify their sellers ranking according to their sales volumes [47]. Africa has an excellent growth record of $25.8 \%$ as against the rest of the world's growth rate of $16.8 \%$ [28]. This Africa success record has infected Nigeria, and according to the Business Day, e-commerce market is advancing in growth with $25 \%$ rate per year and beyond $\$ 255$ billion annual market potentials [26]. Despite the benefits of e-commerce to the sellers, buyers, and the society, the ucommerce added the advantages of over-the-top convenience, customization, value creation, interoperability, and efficient usability. The relevance of u-commerce is not without a challenge of privacy concern [13]. There is a gap in the convergence of ucommerce in the developing countries most especially Nigeria, and since its population has been projected to reach 440 million in the year 2050, u-commerce will be one of the panacea to cater for a large number of online shopper's inflows [46].

Some studies have focused on m-commerce in Nigeria. Ayo et al. [1], examined the prospects of m-commerce in Nigeria using SWOT analysis as an evaluation technique to ascertain the strengths, weaknesses, opportunities, and threats of $\mathrm{m}$ commerce. They discovered that the diffusion of mobile devices in Nigeria is a force and harbinger of possibilities for m-commerce implementation but the major threats are insecurity, constant power outage, and high cost of services. Obe and Balogun, [43] study was related to Ayo et al. [1] as they investigate the practice of mcommerce in Nigeria with a focus on enabling technologies and emerging applications. Obe, and Balogun, [43] discovered a digital divide in Nigeria m-commerce despite its progress and suggested information technology awareness with politicians at the forefront. They also recommend security and privacy study to the future research. A year later, Charles et al. [10] studied the prospects of e-commerce and its inhibitors with PEST (Political, Economic, Social, and Technological) analysis technique. Flavian et al. [16] found that Automatic Teller Machine (ATM) is the most popular mode of payment and argues that ATM not suitable for e-commerce implementation. A few years later, the merchants and vendors of e-commerce switch over to cash-on-delivery payment method to allay the fear of online payment insecurity. Fornell et al. [17] examined two opposite view of risk and trust about online shoppers and vendors. To resolve the discrepancy of risk and trust, Fornell et al. [17] suggest quick government intervention with a solution to legal issues that surround ecommerce operations and success in Nigeria. Gabriel et al. [20] had a reflection of online shopping in Nigeria and discovered the infancy of online shopping while compared with the developed countries.

This study discovered a gap in rigorous statistics data analysis using advanced data analysis technique like Structural Equation Modelling (SEM) to evaluate the security concerns of consumers using ubiquitous computing technology such as u-commerce in Nigeria, and it is the intention of the study to fill this gap by employing VarianceBased-SEM. This study is theoretical and empirically driven, as it applied the integration theory of usability, privacy, trust, reputation, and experience to prove their association. The study argues that u-commerce experience in Nigeria context will posi- 
tively influence the existing m-commerce and the study found that trust is the highest predictor of a reputable u-commerce in Nigeria. The study advance with literature reassessment, explore methodology, present data analysis results, gives theoretical contribution and implications and finally pinpoint the limitations and propose future studies.

\subsection{Users experience: usability, trust, privacy, and reputation in u-commerce}

Usability. Usability is the degree in which a product can be used in a specific application context by a specific user to achieve a specific goal with effectiveness, efficiency, and satisfaction [3]. Usability is commonly understood as a broad notion indicating the quality-in-use of interactive systems [3], [31]. Various definitions exist in literature on usability [31], [42]. Nielsen [42] defining usability from a larger part of a view, that it is envisaged as fine and functional user interface positioning all probable usability issues. Similarly, Nielsen [42] suggested many guidelines for usability, as a learning ability, user-friendliness, well integration of functions, ease of navigation, consistency of the design as assistance for the designers.

Surveys of mobile internet users indicate usability is the biggest source of frustration [15], [48], [58]. Before mobile commerce merchant can address the usability challenge, and before the benefits of u-commerce can be leveraged, the effect of its usability on shoppers' experience would need to be adequately addressed. The study, therefore, hypothesized that;

H1: Usability of ubiquitous mobile devices will positively influence the shopping experience of $\mathrm{u}$-commerce users.

Privacy. The longing of the people to make a choice freely, in different situations and the degree of exposing themselves, their attitude, and their behavior to others is referred to as privacy [62]. According to McCloskey [39], privacy exists when consumers can control their personal information or restrict the use of their personal information [11]. Galanxhi and Fiona [18] found in their study that decision to conduct e-commerce transactions by internet users are influenced by privacy concerns. In the context of mobile money, Kumar, and Riti [32] found out that privacy concern positively influences user experience. In this study, privacy confidence of online shopping is hypothesized to positively affect the experience of customers. The authors therefore hypothesized thus;

H2: Privacy confidence of online shopping will positively enhance the experience of u-commerce users.

Reputation. Casalo et al. [12] defined reputation as a measure of a company's credibility, which results from the relationship among the company's promises and fulfilment. Extant studies have shown the relationship between reputation and consumer trust [24], [64]. Studies such as in [35], [21], [45] further indicates that positive reputation of online service providers significantly influenced consumers' trust in online vendors. Positive company reputation results in a trusting relationship between the consumers and the company while the existence of a negative business reputation results in a less trusting relationship [4]. Since relationship exists between reputation, 
trust, and experience as evident in previous studies, this study further validates the claim and hypothesized that:

H3a: The reputation of merchants and vendors of u-commerce will positively influence the confidence of customers.

$H 3 \mathrm{~b}:$ The higher the reputation, the stronger the relationship between trust and $u$ commerce experience.

Trust. In an online environment, trust has been found to be significant in decision making for online transactions [5], [52]. Flavian et al. [16], Qureshi et al. [49] have also found trust to be a key predictor of both initial online purchase and repeat purchase.

Surveys show that the success of current online shopping sites is primarily attributed to the fact that they earned the trust of users [49]. On the other hand, lack of consumer trust has been identified as one of the greatest barriers hindering online commercial transactions [29], [14]. It is an important predictor of online consumer behavior as it influences the intended use of an e-commerce website [49]. According to Ha and Stoel, [22] consumers thus rely upon their trust in the vendor or the internet to mitigate the effects of their uncertainty toward their relationships (as buyer and seller) in the online environment. Since customers trust can affect their experience, the study thus hypothesized that;

H4: A trusted u-commerce platform will positively influence online shopper's experience.

User's experience. User experience is referred to as the perception an individual form from using or anticipated use of a product, service or an information system [32]. According to Olaleye et al. [44], the user experience is all encompassing as it affects the emotion and the attitude of the user of a product or services. It was further stressed that taking the user experience serious will lessen system user's complaints, brand switch and customer's churning while its neglect will be devastating to the company progress. User experience in this study is a dependent variable. The ucommerce experience determines the degree of trustworthiness and the rate of usability. The study thus hypothesized that:

H5: The higher the ubiquitous experience, the stronger the relationship between trust and usability.

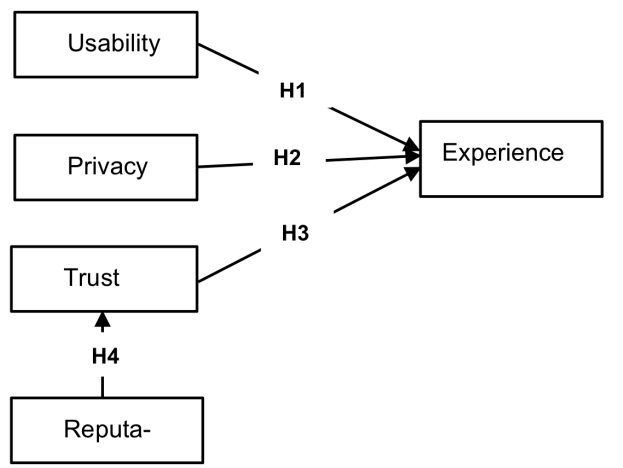

Fig. 1. Conceptual framework and hypotheses (Model A) 


\section{$3 \quad$ Research design and methodology}

\subsection{Questionnaire development}

The study adapted questions from the extant studies to pave the way for validity and used 7-point Likert scales ranging from strongly disagree as the lowest to strongly agree as the highest scales. Usability from Lewis et al. [34], trust, Lin and Wang [37], privacy and reputation, Teo and Liu [54], experience, Li et al. [36]. Demographic questions were added to the questionnaire on gender, age brackets, status, and mobile devices use (see table 1).

\subsection{Sample and data collection}

The study used the quantitative method and targeted the mobile device users for online shopping in Nigeria with convenience sampling technique. The survey was conducted in the South-West geopolitical zone of Nigeria since there are many settlements of the mobile commerce merchants and vendors there than other geopolitical zones of the country. The study utilized paper questionnaire in Nigeria because it is straightforward to use than online survey due to erratic power supply and inconsistent internet connectivity. The study opts for this zone also due to the high literacy level, which facilitates easy communication in the English language. The participants $(n=383)$ varied in sex and status. Male constitute $59.5 \%$, female $40.5 \%$. The respondents, $331(86.4 \%)$ indicates that they are using the tablet while $52(30.6 \%)$ are smartphone users (see table 1). The study respondents have engaged themselves in online shopping with tablet/smartphone/laptop and indicate online shopping experience, purchased electronics, books, kitchen utensils and other items. The data collected was analyzed using SmartPLS 2.0 with partial least square structural equation modelling. The authors also examined the interaction effect of trust, experience, and reputation with SmartPLS 2.0. The study chooses SmartPLS statistics software because it is easy to use and have a potential to solve complicated problems statistically. However, it has its own limitation, but extant studies have recommended it as a useful software [49], [26], [40].

\section{Study Demography}

Table 1. Demography overview

\begin{tabular}{|l|c|c|c|}
\hline Demography Variable & Demography Classification & Frequency & Percentage\% \\
\hline Age & $<25$ & 317 & 82.8 \\
& $25-34$ & 49 & 12.8 \\
& $35-44$ & 14 & 3.7 \\
& $55-64$ & 2 & 0.4 \\
& 65 & 1 & 0.3 \\
\hline Gender & \multicolumn{2}{|l|}{228} & 59.5 \\
& Male & 155 & 40.5 \\
\hline Education & Female & 248 & 64.8 \\
\hline
\end{tabular}


Paper-Experience of Ubiquitous Computing Technology Driven Mobile Commerce in Africa: Impact ...

\begin{tabular}{|l|l|c|c|}
\hline & High School/Diploma & 95 & 24.9 \\
& Master's Degree & 21 & 5.5 \\
& NCE & 1 & 0.2 \\
& PhD & 11 & 2.8 \\
& No Formal Education & 7 & 1.8 \\
\hline Tablet or Smartphone & Tablet & 331 & 86.4 \\
& Smartphone & 52 & 13.6 \\
\hline
\end{tabular}

Table 2. Descriptive statistics and items factor loading

\begin{tabular}{|c|c|c|}
\hline Measurement & F-Loading & Mean (SD) \\
\hline \multicolumn{3}{|l|}{ Usability } \\
\hline This u-commerce platform is easy to use & 0.7796 & $5.38(1.55)$ \\
\hline It is easy to become skillful at using this u-commerce platform & 0.7731 & $5.22(1.55)$ \\
\hline Learning to operate this $\mathrm{u}$-commerce platform is easy & 0.843 & $5.36(1.52)$ \\
\hline This u-commerce platform is flexible to interact with & 0.8173 & $5.20(1.52)$ \\
\hline My interaction with this u-commerce platform is clear and understandable & 0.8554 & $5.44(1.57)$ \\
\hline \multicolumn{3}{|l|}{ Experience } \\
\hline How do you evaluate your usage of u-commerce platform? & 0.8776 & $5.09(1.65)$ \\
\hline $\begin{array}{l}\text { How satisfied are you with your search for information on the u- } \\
\text { commerce platform? }\end{array}$ & 0.8396 & $5.23(1.42)$ \\
\hline $\begin{array}{l}\text { Generally, how do you evaluate your experience with this u-commerce } \\
\text { platform? }\end{array}$ & 0.8773 & $5.19(1.38)$ \\
\hline \multicolumn{3}{|l|}{ Privacy } \\
\hline $\begin{array}{l}\text { I am confident that I know all the parties who collect the information I } \\
\text { provide during the use of this u-commerce platform }\end{array}$ & 0.7957 & $4.13(1.71)$ \\
\hline $\begin{array}{l}\text { I am aware of the exact nature of information that will be collected during } \\
\text { the use of this u-commerce platform }\end{array}$ & 0.8226 & $4.80(1.49)$ \\
\hline $\begin{array}{l}\text { I am not concerned that the information I submitted on this u-commerce } \\
\text { platform could be misused }\end{array}$ & 0.5694 & $4.10(1.68)$ \\
\hline $\begin{array}{l}\text { I believe there is an effective mechanism to address any violation of the } \\
\text { information I provide to this u-commerce platform }\end{array}$ & 0.7256 & $4.81(1.50)$ \\
\hline \multicolumn{3}{|l|}{ Reputation } \\
\hline This u-commerce vendor is well known & 0.7999 & $5.23(1.57)$ \\
\hline This u-commerce vendor has a good reputation & 0.8561 & $5.31(1.46)$ \\
\hline This u-commerce vendor has a reputation for being honest & 0.8515 & $5.15(1.47)$ \\
\hline This u-commerce vendor has a reputation for caring about its customers & 0.8657 & $5.03(1.48)$ \\
\hline $\begin{array}{l}\text { This u-commerce vendor has a reputation for being able to meet its obliga- } \\
\text { tions towards the customers }\end{array}$ & 0.8597 & $5.18(1.38)$ \\
\hline This u-commerce vendor has a reputation for being consistent & 0.8261 & $5.21(1.40)$ \\
\hline \multicolumn{3}{|l|}{ Trust } \\
\hline This u-commerce platform is trustworthy & 0.8523 & $5.06(1.65)$ \\
\hline This u-commerce platform keeps promises and commitments & 0.8706 & $5.01(1.54)$ \\
\hline This u-commerce platform keeps my best interests in mind & 0.848 & $4.86(1.43)$ \\
\hline This u-commerce platform meets my expectations & 0.8193 & $5.17(1.38)$ \\
\hline
\end{tabular}




\section{$4 \quad$ Results}

In the study model, there are five interconnected latent variables, and they are based on well-grounded theories and approaches in m-commerce users' experience in the context of developing country. Based on factor analysis conducted with a SmartPLS, some manifest variables that are not consistent with the model were removed so that the data can fit the model accurately [57]. The study tested the model with a SmartPLS algorithm for reliability, convergent validity and discriminant validity (see tables 2 and 3 for details). Table 4 and 5 revealed the result of the study analysis. The factors loaded well within the acceptable thresholds $(0.56-0.87)$ and the composite reliability of all the latent variables is greater than the threshold of 0.7 . The variance extracted passed the set rule of thumb of 0.5 [6]. The reliability test of Cronbach's alpha that explains the relationship of latent variables and the manifest indicators conform to the verdict of 0.7 [58]. Table 3 is the discriminant table as suggested by [19] with the square root of average variance extracted on bolded diagonal. Additionally, the relationship between trust and experience of u-commerce was mediated by reputation. As Figure 3 illustrates, the standardized regression coefficient between trust and experience was statistically significant. The standardized direct and indirect paths were significant. The authors tested the significance of the indirect effect using bootstrapping procedures, and the result reveals full mediation effect (see Table 4 for details). Figure 4 also depicts how user experience moderates the relationship between trust and usability.

Table 3. Reliability, Validity and Latent Variable Correlations

\begin{tabular}{|l|c|c|c|c|c|c|c|c|}
\hline Construct & CA & CR & AVE & Usability & Experience & Privacy & Reputation & Trust \\
\hline Usability & 0.8728 & 0.9076 & 0.6632 & $\mathbf{0 . 8 1 4}$ & & & & \\
\hline Experience & 0.8325 & 0.8991 & 0.7483 & 0.4865 & $\mathbf{0 . 8 6 5}$ & & & \\
\hline Privacy & 0.718 & 0.8219 & 0.5401 & 0.4637 & 0.4656 & $\mathbf{0 . 7 3 5}$ & & \\
\hline Reputation & 0.9188 & 0.9366 & 0.7115 & 0.6718 & 0.5027 & 0.5882 & $\mathbf{0 . 8 4 4}$ & \\
\hline Trust & 0.8693 & 0.9108 & 0.7187 & 0.6881 & 0.5364 & 0.574 & 0.7794 & $\mathbf{0 . 8 4 8}$ \\
\hline
\end{tabular}

*Square root of Average Variance Extracted on diagonal

\subsection{Hypotheses testing}

Table 5 demonstrates the study model path coefficients and its variation. The usability of ubiquitous mobile devices will positively touch on the shopping experience of mobile commerce users, that is, Usability $\rightarrow$ Experience $\beta=0.19$ and $t=2.89$, the result is significant at $\mathrm{p}<0.01$ and privacy confidence of online shopping will positively enhance the experience of mobile commerce customers, that is, Privacy - $>$ Experience $\beta=0.22$ and $t=3.25$, the result is significant at $\mathrm{p}<0.01$. The reputation of merchants and vendors of mobile commerce will positively influence the online shoppers experience, Reputation $->$ Trust $\beta=0.78$ and $t=28.13$, the result is significant at $\mathrm{p}<0.01$. A trusted mobile commerce platform will positively enhance the confidence of mobile commerce users for online shopping. There is full mediation 
effects between trust and experience, Trust $->$ Experience $\beta=0.34$ and $t=4.36$, the result is significant at $p<0.01$. Experience moderates the relationship between Trust and Usability, Trust*Experience $->$ Usability $\beta=-0.09$ and $t=2.20$, the result is significant at $\mathrm{p}<0.05$. According to [66], the moderation has a quasiinteraction/moderation effects. Both the path of experience and trust are significant to usability. Reputation is the strongest predictor of trust $\beta=0.78$ while usability is the lowest predictor of experience with $\beta=0.19$. [67], [68], [69] emphasized the importance of $\mathrm{R}^{2}$ and posits 0.75 as substantial, 0.50 as moderate, and 0.25 as weak rule of thumb for a model goodness of fit.

Trust has the highest variance, and it explains $\left(\mathrm{R}^{2}=60.7 \%\right)$. The trust $\mathrm{R}^{2}$ is higher than the moderate threshold. Mobile commerce experience in the context of Nigeria explains $\left(\mathrm{R}^{2}=34.5 \%\right)$ variance of the entire model. The $\mathrm{R}^{2}$ for experience is higher than the weak verge of 0.25 . Hypotheses $1-4$ tested are supported.

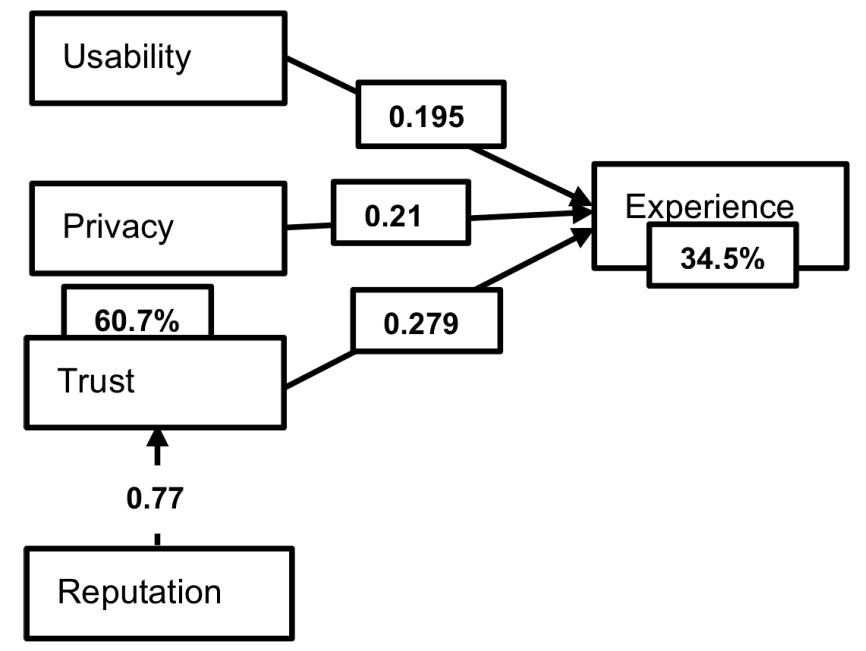

Fig. 2. Conceptual framework and tested hypotheses (Model B)

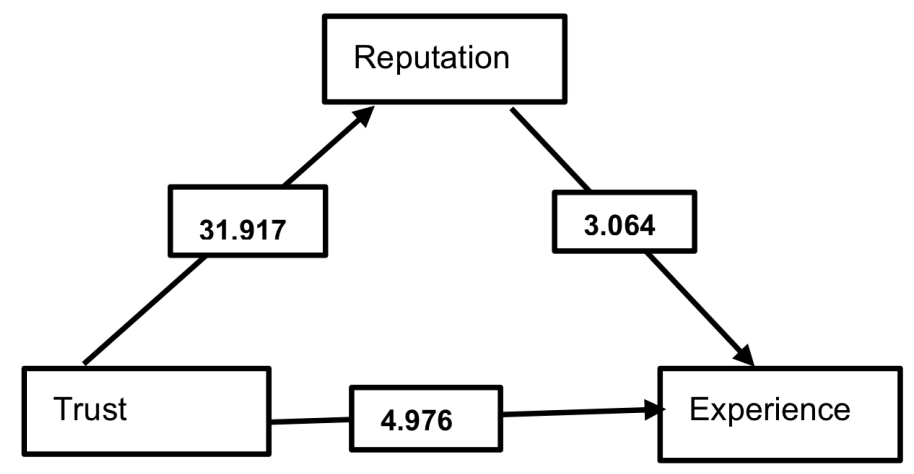

Fig. 3. Model B: Full Mediation with Interaction Effect (Model C) 


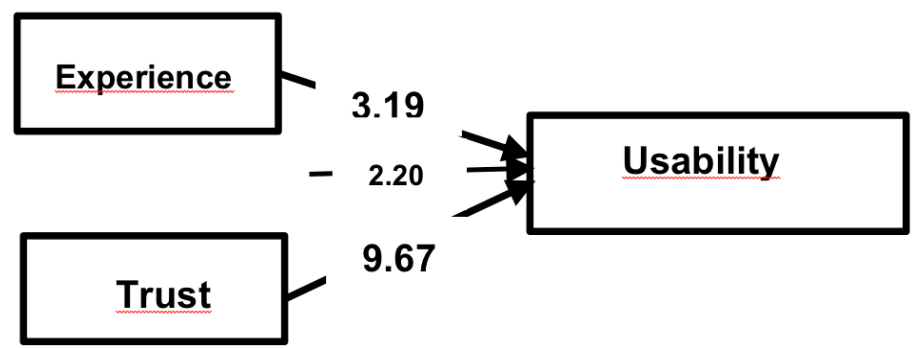

Fig. 4. Quasi Interaction/Moderation Effects (Model D)

Table 4. Standardized direct, indirect and total effects in model C

\begin{tabular}{|l|l|c|c|c|}
\hline Ubiquitous Commerce Model & \multicolumn{1}{|c|}{ Path } & Direct effect & Indirect effect & Total effect \\
\hline $\mathrm{B}$ & Trust $\rightarrow$ Experience & 0.54 & 0.34 & 0.74 \\
& Trus $\rightarrow$ Reputation & 0.77 & - & - \\
& Reputation $\rightarrow$ Experience & 0.52 & - & - \\
& $\mathrm{A}^{*} \mathrm{~B}$ & - & - & 0.40 \\
\hline
\end{tabular}

According to Hair, Hult, Ringle and Sarstedt (2016), the mediation analysis can be computed as $(\mathrm{P} 1 \times \mathrm{P} 2=0.77 \times 0.52)$ for indirect effect and $\mathrm{P} 3+(\mathrm{P} 6 \times \mathrm{P} 17)=0.34+$ $(0.77 \times 0.52)=0.34+0.40=0.74$ for total effect. The result established mediation effects between trust and experience through reputation and the total effect of the mediation is stronger (Details in Fig. 3 and Table 4).

Table 5. Standardized path coefficients and corresponding hypothesis results

\begin{tabular}{|c|c|c|c|c|c|cc|}
\hline Hypotheses & Path Coefficient & Beta & STDEV & T-Test & Result & P. Value \\
\hline H1 & Usability -> Experience & 0.1949 & 0.0674 & 2.8903 & Accepted & 0.002 & $<.01$ \\
\hline H2 & Privacy -> Experience & 0.2152 & 0.0662 & 3.2503 & Accepted & 0.0006 & $<.01$ \\
\hline H3a & Reputation -> Trust & 0.7794 & 0.0277 & 28.132 & Accepted & $0.00001<.01$ \\
\hline H3b & Reputation**Trust -> Experience & 0.3316 & 0.076 & 4.3642 & Accepted & 0.0016 & $<.01$ \\
\hline H4a & Trust -> Experience & 0.2788 & 0.0829 & 3.3632 & Accepted & 0.0004 & $<.01$ \\
\hline H4b & Trust*Experience -> Usability & -.0896 & 0.0407 & 2.2031 & Accepted & 0.0282 & $<.05$ \\
\hline
\end{tabular}

\section{Discussion and implications}

This study analyzed the impact of usability, privacy, trust, and reputation on user's u-commerce experience. The study adopts an empirical perspective in u-commerce service and uses an integrated model to identify the impact of m-commerce user's specific behavior. The factors employed in this study were classified as convenience, confidence, and eminent factors based on the user's u-commerce experience. The study results confirmed the significant role of trust as a mediator between the reputation and u-commerce user's experience, and usability and privacy directly predict the u-commerce user's experience. 
Additionally, among the factors, eminent factor such as reputation have significant positive effects on confidence, experience and trust, which emphasizes the interconnectivity of a reputable merchants and vendors with a trusted u-commerce platform and the necessity of privacy and trust assurance to boost effective user's experience of u-commerce [63], [51]. The empirical study findings also indicate the importance of usability such as convenience and simplicity of u-commerce platform design to attract more users. Despite the versatility of u-commerce, a cumbersome design of $\mathrm{u}$ commerce will deter user's experience [64].

This study theoretically integrates convenience, confidence, and eminent factors as a unified model of ubiquitous commerce experience. The study makes theoretical contributions in four ways. First, the study contributes to the literature by establishing the validity of an integrated model of convenience, confidence, and eminence to explain the user's experience of ubiquitous commerce [63].

Second, the study contributes by examining the relationship between convenience (usability), confidence (trust and privacy) and eminence (reputation) and it is interesting that they all have a significant positive relationship in the context of ubiquitous commerce [3], [38], [53], [54]. Third, the study explicates the direct relationship of usability, privacy to user's experience while trust has an indirect relationship to user's experience. It indicates the importance of a trusted u-commerce for reputable merchants and vendors to make a great impact on ubiquitous commerce user's experience [55]. Lastly, the study reveals the mediation effect of reputation between trust and experience and experience moderates the relationship between trust and usability. There is a strong connection between the trust and the u-commerce experience whenever there is a reputable vendor at the background [7], [58], [8]. Furthermore, whenever there is positive u-commerce experience, it will build a trust that will lead to increase usability.

\subsection{Managerial implications}

Privacy is one of the major concerns of advancement of u-commerce [32]. The ucommerce users want to know why the merchants and the vendors collect, store and use their data and mutual agreement between the provider, and the user of $\mathrm{u}$ commerce regarding privacy is obscure. For example, a country like Nigeria is yet to have a robust cyber and privacy policy that can build u-commerce user's confidence in online shopping. The study offers three managerial implications. First, the merchants, vendors and other u-commerce stakeholders need to innovate the privacy assurance of their online platform as either silent commerce, television commerce or virtual commerce. There should be emphasis that is backed-up with actions. Elements of confidence such as customers' respect, promise without compromise, the demarcation between expectation and reality should reflect in their privacy policy. Second, the merchants, vendors and the other stakeholders should maximize the integration of $\mathrm{u}-$ commerce applications and make use of it to solve the problem of theft, shoplifting, logistics, stocktaking, and fraud detection. Three, to advance commerce digitization and to increase revenue in a developing country such as Nigeria, the mobile commerce practitioners need to pay attention to u-commerce strategy as technology ubiq- 
uity convergence will help in differentiation, cost leadership, and focus strategies. They also need to be tactful in ubiquitous commerce execution. They can use one service provider of u-commerce platform or opt for a combination of u-commerce services based on their customers' base and the needs of their customers. They must ensure they execute a platform that adds value to their services. Lastly, they must be prudent in u-commerce management. Mapping out strategies for content and performance optimization will help them to have a successful implementation of $\mathrm{u}$ commerce while organizational design and change management will be a booster to the u-commerce development.

\subsection{Limitations and future research}

This empirical study dwelled on m-commerce users' experience in Africa context but did not put into consideration the developed nations. This development has created a gap for the scholars to undertake a comparative study on u-commerce between the developing and the developed countries. This type of study will give insight to the advancement of u-commerce globally. In addition, it will be interesting to use categorical variables such as gender, age, education level, and income as a moderator between trust and user's experience. The acceptance of u-commerce based on gender differences will be a welcome idea. The study also used a quantitative method, but it will be insightful for the future researchers to employ mixed methods to study ucommerce convergence and constraints in emerging economy such as Africa. The study on the impact of u-commerce on cart abandonment will be a solution to the widespread cart abandonment in online shopping. The study proposed the following research questions: (1) Why is gender, age, education level, and income an essential moderator of trust and user's experience of u-commerce? (2) How can u-commerce prevent cart abandonment and facilitate quick checkout in online shopping? (3) How can the convergence of u-commerce enhance user's experience and what are the constraints of its divergence in an emerging economy? The future researchers can explore these research questions and contribute to the literature of u-commerce.

\section{References}

[1] Ayo, C.K., Ekong, U.O., Afolabi, I.T and Adebiyi, A.A. "M-commerce implementation in Nigeria: trends and issues. Journal of Internet Banking and Commerce, 12, 2 (2007).

[2] Bright J. An E-commerce Challenge in Africa: Selling to People who aren't Online. Retrieved July 05, 2017, from http://www.newyorker.com/business/currency/e-commercesafrican-challenge-selling-to-people-who-arent-online.

[3] Bevan, N. Measuring Usability as Quality of Use, Software Quality Journal, (1995), 115 150. ISO 9241-11. (1998). ISO. Retrieved from ISO http://www.iso.org/iso/home/store/catalogue_tc/catalogue_detail.htm?csnumber $1 / 416883$.

[4] Beldad, A., de Jong, M. and Steehouder, M. How Shall I Trust the Faceless and the Intangible? A Literature Review on the Antecedents of Online Trust. Computers in Human Behavior, 26, 5 (2010), 857-68. 
Paper-Experience of Ubiquitous Computing Technology Driven Mobile Commerce in Africa: Impact ...

[5] Ba S., Pavlou P., 2006. Evidence of the effect of trust building technology in electronic markets: Price premiums and buyer behavior. Available at SSRN 951734.

[6] Bagozzi, R. P., and Yi, Y. On the evaluation of structural equation models. Journal of the academy of marketing science 16, 1 (1988), 74-94.

[7] Berry, L. L., Lewis, P. C., and Stephan H. H. Managing the total customer experience. MIT Sloan management review 43, 3 (2002), 85.

[8] Anil, B., Kandampully, J. and Zhang, T. Towards a unified customer experience in online shopping environments: Antecedents and outcomes. International Journal of Quality and Service Sciences 8, 1 (2016), 102-119.

[9] Commerce-land, 2004. History of E-commerce. Retrieved July 05, 2017, from http://www.ecommerce-land.com/history ecommerce.html.

[10] Charles, K., Fatudimu I. T. and Uyinomen, O. E. A framework for e-commerce implementation: Nigeria a case study. The Journal of Internet Banking and Commerce 13, 2 (1970), $1-12$.

[11] Culnan, M. J. and Bies, R. Consumer privacy: Balancing economic and justice considerations, Journal of Social Issues, 59, 2 (2003), 323-342.

[12] Casalo, L. V., Flavian, C. and Guinaliu, M. The Influence of Satisfaction, Perceived Reputation and Trust on a Consumer's Commitment to a Website.” Journal of Marketing Communications, 13, 1 (2007), 1-17.

[13] Dinev, T., Bellotto, M., Hart, P., Russo, V., Serra, I. and Colautti, C. Internet users' privacy concerns and beliefs about government surveillance: An exploratory study of differences between Italy and the United States. Journal of Global Information Management, 14, 4 (2006), 57-93.

[14] Dayal, S., Landesberg, H. and Zeisser, M. Building Trust Online. Mckinsey Quarterly. Available at http://www.mckinsey.com/featured-insights, 2001

[15] Forrester R. Segmenting Europe's Mobile Consumers. 2002.

[16] Flavian, C., Guinaliu, M., and Gurrea, R. The Role Played by Perceived Usability, Satisfaction and Consumer Trust on Website Loyalty. Information \& Management, 43 (2006), $1-14$.

[17] Fornell, C. and David F. L. Evaluating structural equation models with unobservable variables and measurement error. Journal of marketing research (1981), 39-50.

[18] Galanxhi, H. and Fiona F-H. N. Privacy issues in the era of ubiquitous commerce. Electronic markets 16, 3 (2006), 222-232.

[19] George, O. J. "Risk and Trust in Online Shopping: Experience from Nigeria. Risk, 11 (2015).

[20] Gabriel, J. M. O., Ogbuigwe, T. D. and Ahiauzu, L. U. Online Shopping Systems in Nigeria: Evolution, Trend and Prospects.

[21] Gregori, N., Daniele, R. and Altinay, L. Affiliate Marketing in Tourism: Determinants of Consumer Trust." Journal of Travel Research, 53, 2 (2014), 196-210.

[22] Ha, S., Stoel, L. Promoting customer-retailer relationship building: Influence of customer trustworthiness of customer loyalty programme marketing. Journal of customer behaviour 7, 3 (2008), 215-229.

[23] Han, T. H., Nguyenb, B. and Lee, T. J. Consumer-based Chain Restaurant Brand Equity, Brand Reputation, and Brand Trust. International Journal of Hospitality Management 50 (2015), 84-93. https://doi.org/10.1016/j.ijhm.2015.06.010

[24] Hsu, M. H., Chang, C. M. Chu, K. K. and Lee, Y. J. Determinants of Repurchase Intention in Online Group- Buying: The Perspectives of DeLone \& McLean IS Success Model and Trust. Computers in Human Behavior 36 (2014), 234-45. 
[25] Hoffman, D.L., Novak, T.P. and Peralta, M. Building Consumer Trust Online, Communications of the ACM, 42, 4 (1999), 80-85.

[26] Hair, J. F., Christian M. R. and Marko S. PLS-SEM: Indeed a silver bullet. Journal of Marketing theory and Practice, 19, 2 (2011), 139-152.

[27] Junglas, I. A. and Watson, R. T. The U-Constructs: Four Information Drives, Communications of the Association for Information Systems, 17 (2006), 569-592.

[28] Ihenyen S. E-commerce evolution in Nigeria: Opportunities and Threats. Retrieved July 05, 2017, from https://www.linkedin.com/pulse/evolution-e-commerce-nigeriaopportunities-threats-senator-ihenyen.

[29] ISO Ergonomic Requirements for Office Work with Visual Display Terminals (VDTs)Part 11: Guidance on Usability, 1998.

[30] Jaydip S. Ubiquitous Computing: Potentials and Challenges. In Proceedings of the International Conference on Trends \& Advances in Computation \& Engineering (TRACE), 2010.

[31] Jakimoski, K. Analysis of the Usability of M-commerce Applications. International Journal of U-and e-Service, science and Technology, 7, 6 (2014), 13-20.

[32] Kumar, R. and Riti C. Shaping ubiquity for the developing world. In International Telecommunications Union (ITU) Workshop on Ubiquitous Network Societies, Geneva, Switzerland. 2005.

[33] Law, E. L. C. The measurability and predictability of user experience. In Proceedings of the 3rd ACM SIGCHI symposium on Engineering interactive computing systems (2011), $1-10$.

[34] Lewis, J. R., Brian S. U. and Deborah E. M. Measuring perceived usability: The SUS, UMUX-LITE, and Alt Usability. International Journal of Human-Computer Interaction, 31, 8 (2015), 496-505.

[35] Li, Y. The impact of disposition to privacy, website reputation and website familiarity on information privacy concerns. Decision Support Systems 57 (2014), 343-354.

[36] Li, M., Dong Z. Y. and Xi C. Factors influencing consumption experience of mobile commerce: A study from experiential view. Internet Research, 22, 2 (2012), 120-141.

[37] Lin, H. H. and Wang, Y. S. An examination of the determinants of customer loyalty in mobile commerce contexts. Information \& management, 43, 3 (2006), 271-282.

[38] Lee, K. J. and Jeong-In J. Incentive-Based and Peer-Oriented Design of Ubiquitous Commerce. In ICEIS 3 (2007) 624-631.

[39] McCloskey, H. Privacy and the right to privacy, Philosophy, 55, 211 (1980), 17-38.

[40] Mousa S. A., Soud M., Amjad F. T. and Almahamid. University website quality characteristics and success: lecturers' perspective. International Journal of Business Information Systems 22, 1 (2016), 41-61.

[41] Nigerian Communications Commission, Accessed on 4th July 2017.

[42] Nielsen, J. Usability Engineering, Morgan Kaufmann, 1994.

[43] Obe, O. O., and Balogun, V. F. Practice, trends and challenges of mobile commerce in Nigeria. Information Technology Journal, 6, 3 (2007), 448-456.

[44] Olaleye, S.A, Sanusi, I.T. and Oyelere S.S. (2017). Users Experience of Mobile Money in Nigeria. IEEE Africon 2017 Proceedings, pp. 929-934. https://doi.org/10.1109/AFRCON. 2017.8095606

[45] Olaleye, S.A., Salo, J. and Ukpabi, D.C. (2018). The Role of Reputation on Trust and Loyalty: A Cross-Cultural Analysis of Tablet E-Tailing. International Journal of E-Business Research (IJEBR), Vol. 14, 2.

[46] Osho, O., Onuoha, C. I., Ugwu, J. N. and Falaye, A.A. E-Commerce in Nigeria: A Survey of Security Awareness of Customers and Factors that Influence Acceptance. In Pro- 
Paper-Experience of Ubiquitous Computing Technology Driven Mobile Commerce in Africa: Impact ...

ceedings of International Conference on Computing Research and Innovations (CoRI 2016), September 7-9,2016, 169-176.

[47] Pasquier M. 2014. E-commerce in Nigeria: How Rocket Internet's Jumia, Kaymu and Jovago are taking over Africa's Biggest Market. Retrieved July 05, 2017, from www.innovationiseverywhere.com/e-commerce-in-nigeria-rocket-internets-jumia-kaymujovago-taking-africas-biggest-market/.

[48] Pelet, J-E and Papadopoulou, P. The effects of e-commerce websites colors upon consumer trust. European Marketing Academy Conference, 2009.

[49] Qureshi, I., Fang, Y., Ramesy, E., McCole, P., Ibboston, P., and Compeau, D. Understanding Online Customer Repurchasing Intention and the Mediating Role of Trust: An Empirical Investigation in Two Developed Countries. European Journal of Information Systems, 18, 3 (2009), 205-222.

[50] Ramsay, M. and Nielsen. J. Déjà Vu. 1994 All Over Again. Nielsen Norman Group, 2000; https://www.nngroup.com/reports/wap-usability/.

[51] Roussos, G. and Theano M. Consumer perceptions of privacy, security and trust in ubiquitous commerce. Personal and Ubiquitous Computing, 8, 6 (2004), 416-429.

[52] Sha, W. Types of structural assurance and the irrelationships with trusting intentions in business-to-consumer e-commerce. Electron. Mark.19, (2009), 43-54.

[53] Sheng, H., Fiona F-H. N., and Keng S. An experimental study on ubiquitous commerce adoption: Impact of personalization and privacy concerns. Journal of the Association for Information Systems 9, 6 (2008), 344.

[54] Watson, T. R., Pitt, L. F., Berthon, P. and Zinkhan, G. M. U-Commerce: Extending the Universe of Marketing. Journal of the Academy of Marketing Science, 30, 4 (2002), 329343

[55] Hi, T. and Wei, J. Impact of Privacy and Security on Users' Trust in Ubiquitous Commerce. IEEE, 11, 2011.

[56] Teo, T. S., and Liu,J. Consumer Trust in E-commerce in the United States, Singapore and China. Omega 35, (2007), 22-38.

[57] Tenenhaus, M., Vincenzo E. V., Yves-Marie C. and Carlo L. PLS path modeling. Computational statistics \& Data analysis, 48, 1 (2005), 159-205.

[58] Tavakol, M. and Reg D. Making sense of Cronbach's alpha. International journal of medical education 2 (2011), 53.

[59] United Nations. World Population Prospects: The 2017 Revision - Key Findings and Advance Tables. United Nations Department of Economic and Social Affairs, Population Division. July 2017. Retrieved 07 July 2017.

[60] Venkatesh, V. Ramesh, V. and Massey, A.P. Understanding Usability in Mobile Commerce, Communications of the ACM, 46, 12 (2003), 53-56.

[61] Worldometers.info, "Nigeria Population 2017 - Worldometers," Accessed on 4th July 2017.

[62] Edwards, W. K. and Grinter, R. E. At Home with Ubiquitous Computing: Seven Challenges. Springer-Verlag Berlin Heidelberg, LNCS, 2201 (2001), 256-272.

[63] Westin, A. The right to privacy. New York: Athenaeum, 1967.

[64] Yoon, C. and Sanghoon K. Convenience and TAM in a ubiquitous computing environment: The case of wireless LAN. Electronic Commerce Research and Applications, 6, 1 (2007), 102-112.

[65] Hair Jr, J. F., Hult, G. T. M., Ringle, C., \& Sarstedt, M. (2016). A primer on partial least squares structural equation modeling (PLS-SEM). Sage Publications. 
[66] Sharma, N. (2003). The role of pure and quasi-moderators in services: an empirical investigation of ongoing customer-service-provider relationships. Journal of Retailing and Consumer Services, 10(4), 253-262. https://doi.org/10.1016/S0969-6989(02)00020-6

[67] Leppäniemi, M., Jayawardhena, C., Karjaluoto, H., \& Harness, D. (2017). Unlocking behaviors of long-term service consumers: The role of action inertia. Journal of Service Theory and Practice, 27(1), 270-291. https://doi.org/10.1108/JSTP-06-2015-0127

[68] Hair, J.F. Jr, Ringle, C.M. and Sarstedt, M. (2011), "PLS-SEM: indeed a silver bullet", Journal of Marketing Theory and Practice, Vol. 19 No. 2, pp. 139-151. https://doi.org/10.2753/MTP1069-6679190202

[69] Henseler, J., Ringle, C.M. and Sinkovics, R.R. (2009), "The use of partial least squares path modeling in international marketing", Advances in International Marketing, Vol. 20 No. 1, pp. 277-319.

\section{$7 \quad$ Authors}

Sunday Adewale Olaleye had a Master of Science in Information Systems from the Abo Akademi University, Turku, Finland. Currently doing his doctoral studies at the Department of Marketing, Management and International Business, Oulu Business School, Finland. He has presented papers in conferences and published in academic journals. His research interests are Emerging Mobile Technologies, Electronic and Mobile Commerce and Mobile Apps. Email: sunday.olaleye@oulu.fi.

Solomon Sunday Oyelere is a postdoctoral researcher at the School of Computing, University of Eastern Finland. His research interests are in the areas of Ubiquitous computing technologies, computer science education, and educational data mining. He has several years of experience as a Lecturer in Computer Science at Modibbo Adama University of Technology, Yola-Nigeria and Dorben Polytechnic AbujaNigeria. Email: solomon.oyelere@uef.fi.

Ismaila Temitayo Sanusi is a PhD student at the Philosophical Faculty, University of Eastern Finland. His research interests are Mobile Technologies, Educational Technology, Entrepreneurship and TVET. He has presented papers in conferences and published in academic journals. Email: ismails@uef.fi.

Agbo Friday Joseph is a $\mathrm{PhD}$ student at the School of Computing, University of Eastern Finland. He has attended and presented papers in conferences and have also published academic papers in journals. His research interests are Mobile Learning Technologies, Smart City, and Smart Learning Environment. Email: fridaya@uef.fi.

Article submitted 28 October 2017. Resubmitted 02 March 2018. Final acceptance 08 May 2018. Final version published as submitted by the authors. 